Schöttle, A., Arroyo, P., Christensen R. (2018). "Demonstrating the value of an effective collaborative decision-making process in the design phase." In: Proc. $26^{\text {th }}$ Annual Conference of the International. Group for Lean Construction (IGLC), González, V.A. (ed.), Chennai, India, pp. 899-909. DOI: doi.org/10.24928/2018/0500. Available at: www.iglc.net.

\title{
DEMONSTRATING THE VALUE OF AN EFFECTIVE COLLABORATIVE DECISION- MAKING PROCESS IN THE DESIGN PHASE
}

\author{
Annett Schöttle ${ }^{1}$, Paz Arroyo $^{2}$, and Randi Christensen ${ }^{3}$
}

\begin{abstract}
Decisions are the foundation for creating value in a project. Particularly in the early design phases, decisions form and restrict the value creation processes throughout the project's life cycle Therefore, project teams should pay attention to the decision-making process, and design it to secure maximum value creation and clear documentation. This paper shows and analyses the decision-making process in the design phase of four different projects based on four characteristics: (1) decision-making method, (2) structure of the decision-making process, (3) governance process, and (4) documentation process. Our findings demonstrate that all four characteristics are essential and need to be considered when designing the decision-making process. Furthermore, the results demonstrate that making decisions collaboratively will lead to value adding opportunities. Consequently, this paper explains how the decision-making process affects the value creation process and gives insights on how to design it in an effective manner.
\end{abstract}

\section{KEYWORDS}

Choosing by Advantages, collaboration, decision-making, integration, value

\section{INTRODUCTION}

"A decision is a choice made from among alternatives proposals, and the consideration of these proposals constitutes all parts of the group's task performance" (Ellis and Fisher 1994). "It is a product of the cognitive processing of information, norms influencing the nature of social interaction, the skills, traits, and dispositions of individual group members" (Guzzo 1982). Both quotes show the complexity of group decision-making. In the Lean Construction community, many papers have been published understanding and explaining the concept of value (see Salvatierra-Garrido et al. 2012; Table 1). In comparison, searching for terms such as 'decision', 'decision-making', or 'decisionmaking process', in the title, abstract, or keywords of the last 25 years IGLC papers results in fewer findings, and the combination of those with 'value' leads to almost no

PhD Candidate at Karlsruhe Institute of Technology (KIT)and Senior Consultant at Refine Projects AG, GER, annett.schoettle@ protonmail.com, Advisor: Prof. Dr.-Ing. Fritz Gehbauer, M.S.

2 Senior Coach, Lean Project Consulting, USA, parroyo@leanproject.com

3 Lean Manager, Lower Thames Crossing, COWI, UK, RMCH@cowi.com 
results. If the term 'decision making method' was insert, it always lead to articles on 'Choosing by Advantages' (CBA).Moreover, Salvatierra-Garrido et al. 2012 analyzed IGLC papers from 1996 to 2011 and identified 52 papers to have a deeper look into the conceptualization of value. Only one of those papers were related to the design phase. A paper written by Tzortzopoulos and Formoso (1999) already pointed out the importance of the decision-making process in the design phase. Nevertheless, there is little research about the value creation through decision-making processes in the design phase.

Table 1: Hits per terms from IGLC papers 1996 to 2017 (1433 total papers)

\begin{tabular}{ccccc}
\hline Terms & Hits & $\%$ & combined with 'value' \\
& & & Hits & $\%$ \\
\hline value & 450 & 31,40 & - & - \\
decision & 187 & 13,05 & 9 & 0,63 \\
decision-making & 47 & 3,27 & 3 & 0,21 \\
decision-making method & 7 & 0,49 & & \\
decision-making process & 13 & 0,91 & & \\
CBA & 14 & 0,98 & $\mathbf{0}$ & $\mathbf{0}$ \\
\hline
\end{tabular}

We argue that how the project team decides on design alternatives is crucial for the project's success. The decision-making process makes the foundation for the creation of value for the client and sets the standard for how efficiently the supply chain will be able to deliver. To further explore this, the research consists of a literature review and a crosscase analysis to answer the following research questions: (1) What creates value in the decision-making process? (2) What is needed to make decisions effectively? (3) How should the decision-making process be designed? Based on the findings, the research questions will be discussed, and conclusions will be drawn.

\section{LITERATURE REVIEW}

\section{EFFECTIVE GROUP DECISION-MAKING PROCESS}

A group decision requires the involvement of all team members to increase the decision quality and the commitment to implement the decision (Johnson and Johnson 2009). Johnson and Johnson (2009) define five major characteristics which impact the effectiveness of a group decision: (1) the resources available to the group are fully utilized (2) time is well used, (3) the decision is correct or of high quality, (4) the decision is implemented fully by all required group members, and (5) the problem-solving ability of the group is improved, or at least not lessened. Therefore, (6) communication among the team members is essential for effective group decision to be made (Hirokawa 1990), and (7) coordination of interdependencies, goals, information, and perspectives sharing among team members is necessary (Kolb and Boos 2009). Moreover, Van Wee and Priemus (2017) state that the democratic quality of a group decision increases if the process is "based on an [(8)] adequate method and in a neutral, independent way, making 
clear what the impact will be of each alternative" (Van Wee and Priemus 2017). Other factors impacting the effectiveness can be clustered in (9) type and characteristic of decision task like structure, information requirements, and the evaluation demand (Hirokawa 1990), (10) characteristics of the process like available information resource, quality of the effort to come to a decision, decision logic (Hirokawa et al. 1996), conflict management, individual incentive (Johnson and Johnson 2009), (11) characteristic of the team members like personality (Ellis and Fisher 1994), relevant skills, uncritically dominant responses, egocentrism, production blocking (Johnson and Johnson 2009), thinking quality (Hirokawa et al. 1996), (12) characteristic of the group like group size, lack of group maturity, sufficient heterogeneity (Johnson and Johnson 2009), and (13) group phenomenon like social loafing, free riding, sucker effect, concurrence seeking, or cognitive dissonance (Johnson and Johnson 2009).

Based on the listed aspects it gets obvious that group decision-making requires a wellestablished process that considers certain social and structural factors, because they are affecting the input, process, and the output of the decision. However, the big advantage of a group decision-making process is the increased quality and acceptance of the decision (Johnson and Johnson 2009).

\section{VALUE OF IMPLEMENTING CHOOSING BY ADVANTAGES (CBA)}

Decision-making methods impact the result of the decision (Dean and Sharfman 1996; Schöttle and Arroyo 2017) and therefore it is important to implement a method which supports the process. Decision-makers often use a cost-benefit analysis to decide between alternatives. This can be problematic because "[c]ost-benefit analysis covers efficiency and effectiveness (...) but not fairness, but it was never designed to do this. (...) [This implies] that if ethical issues are at stake, a cost benefit analysis alone is not sufficient in preparing decision making" (Van Wee and Priemus 2017). CBA is a multi-criteria decision-making method that, based on an anchored judgement, compares the advantages of alternatives (Suhr 1999). Different studies have compared CBA to other decisionmaking methods such as weighting rating calculating (WRC), or analytical hierarchical process and presented the benefits of CBA over those methods (Arroyo et al. 2014; Schöttle and Arroyo 2017). For example, Arroyo et al. (2016) did a practical experiment and found that the teams achieved faster consensus and felt less frustration by using CBA in comparison to WRC. Based on high detailing manner, much effort is needed upfront to develop the decision and discuss intensively the advantages of the alternatives. This leads to constructive debates, a better understanding of what is wanted, less misinterpretation, and a very transparent process (Schöttle and Arroyo 2017). Some studies have already discovered those effects for design decisions (Arroyo et al. 2014; Kpamma 2016).

\section{RESEARCH METHOD FOR CASE STUDIES}

The authors used case study research and action research as strategy in dependence of the project status. The case study research was used to get a better understanding of the decision-making process in construction projects, because it allows researchers an indepth investigation of a particular issue (Yin 2014). Action research is used when the researcher investigates an issue and takes action in the project based on the findings 
(Dickens and Watkins, 1999). Table 1 shows which strategy and methods were used to collect and analyze the data. In Case 1 and 2, interviews were conducted from October to November 2014. The interviews were transcribed and analyzed using qualitative content analysis based on Mayring (2010). Case 3 and 4 are ongoing projects. The researchers used action research that involves surveys, discussions, mails, meeting evaluation, and observations to generate direct feedback to intervene in the process. In case 3 the research was collected by the Lean Manager on the project. In case 4 the data was collected by the CBA expert of the project.

Table 1: Research methods of the case studies

\begin{tabular}{|c|c|c|c|c|c|}
\hline Case & Location & Status & $\begin{array}{l}\text { Research } \\
\text { strategy }\end{array}$ & Data collection & Data analysis \\
\hline $\begin{array}{c}\text { (1) UCSF Mission } \\
\text { Hall }\end{array}$ & $\begin{array}{c}\text { San } \\
\text { Francisco }\end{array}$ & completed & Case study & $\begin{array}{c}\text { documents, open-ended } \\
\text { interviews }\end{array}$ & $\begin{array}{c}\text { Qualitative } \\
\text { content analysis }\end{array}$ \\
\hline $\begin{array}{l}\text { (2) UCSF Medical } \\
\text { Centre }\end{array}$ & $\begin{array}{c}\text { San } \\
\text { Francisco }\end{array}$ & completed & Case study & $\begin{array}{l}\text { documents, open-ended } \\
\text { interviews }\end{array}$ & $\begin{array}{c}\text { Qualitative } \\
\text { content analysis }\end{array}$ \\
\hline $\begin{array}{l}\text { (3) Lower Thames } \\
\text { Crossing }\end{array}$ & London & ongoing & $\begin{array}{l}\text { Action } \\
\text { research }\end{array}$ & $\begin{array}{l}\text { Surveys, meeting } \\
\text { evaluations }\end{array}$ & $\begin{array}{l}\text { Grounded } \\
\text { Theory }\end{array}$ \\
\hline $\begin{array}{l}\text { (4) IT Campus } \\
\text { Project }\end{array}$ & $\begin{array}{c}\text { San } \\
\text { Francisco }\end{array}$ & ongoing & $\begin{array}{l}\text { Action } \\
\text { research }\end{array}$ & $\begin{array}{c}\text { observation, } \\
\text { documentation, interviews }\end{array}$ & $\begin{array}{l}\text { Grounded } \\
\text { Theory }\end{array}$ \\
\hline
\end{tabular}

\section{CASE STUDIES}

Table 3 gives an overview of the four case studies.

Table 3: Overview of the case studies

\begin{tabular}{ccccc}
\hline Case & $\begin{array}{c}\text { UCSF Mission } \\
\text { Hall }\end{array}$ & $\begin{array}{c}\text { UCSF Medical } \\
\text { Center }\end{array}$ & $\begin{array}{c}\text { Lower Thames } \\
\text { Crossing }\end{array}$ & IT Campus Project \\
\hline Project type & Public & Public & Public & Private \\
$\begin{array}{c}\text { Project } \\
\text { characteristic }\end{array}$ & Office Building & Hospital & $\begin{array}{c}\text { Tunnel and } \\
\text { connecting roads }\end{array}$ & Office Building \\
Project completion & November 2014 & February 2015 & Planned 2027 & Planned 2019 \\
Construction & August 2012 & January 2009- & Preliminary design & Preliminary design \\
documents & February 2013 & August 2010 & started 2017 & started 2015 \\
Project budget & US\$ 93,8M & US\$ 1,52B & US\$ 6 - 8.6B & Unknown \\
Co-location & Yes & Yes & Yes & Virtual \\
BIM & Yes & Yes & Yes & Yes \\
LPS & Yes & Yes & Yes & Yes \\
\hline
\end{tabular}

\section{CASE 1}

UCSF Mission Hall is an academic office building located at the UCSF Mission Bay campus in San Francisco that opened in September 2014. The building contains mostly open and activity-based workstations, a conference center as well as classrooms at the first level and a cafe. Major design decisions were made during the tendering phase in which the DB team had to develop the design. However, during the design phase 
decisions had to be made very fast because of the schedule. Therefore, major actions of decisions were tracked with the LPS. Priorities in the decision-making process were quality and the project being delivered within budget. Depending on the issue, decisions were made sometimes collaboratively and sometimes from the top-down, such as a decision that resulted in a design change. The team used A3 reports to decide between alternatives in the design phase. The A3 reports summarized issues, the background, current conditions, an analysis using 5 Whys, target conditions, the proposed countermeasures, and the implementation plan showing the status of the decision with due date and contributors. Interviewees stated that CBA was used in those A 3 reports, but this wasn't the case. Decisions were made based on defined advantages and disadvantages of alternatives. The cost of every alternative was displayed. Other decisions were made in meetings through discussion about the work scope and costs in the team. Subcontractors often prepared data sheets, presented alternatives and indicated a suggestion. One interviewee described the decision-making process as follows: "We just sat in that room, we decided what the best options were [and] we ran over options, which we thought would be the best." Other interviewees described the decision-making process as a negotiation to find the best solution. The team was aware that decisions contained lots of information from different individuals because of interdependencies. Therefore, the scope between the participants needed to be balanced and the cost impact considered. Not always was the right team member in the room to proceed with the decision, because of a lack of manpower, which was inefficient. Nevertheless, the team managed to make decisions on time. In the OAC meeting, alternatives were discussed with the owner and the owner made the final decision.

\section{CASE 2}

The UCSF Mission Bay Medical Centre is a complex building which consists of hospitals specializing in children, women, and cancer, and an energy center. The hospital opened in February 2015. At the time, the team co-located on site in June 2009, 95\% of design development was completed. The public project consisted of many challenges. One challenge was to design just enough to get the permit, with the knowledge that the design will change based on the evolution of the equipment, because the technology in the healthcare industry is changing rapidly. To handle the ideas and innovations and to work productively through the design phase, the team developed a decision-making process to make timely decisions at the lowest responsible level. The decision-making process consisted of four hierarchical levels: (1) individual cluster group, (2) captains level, (3) senior leadership principles, and (4) management committee. The cluster group consisted of the eight divisions: site, structural, exterior wall, M\&P, electrical/ low voltage, special systems, interiors, equipment, and focused on the technical issues. They interacted, discussed, negotiated, and traded targets to move forward and meet the budget. If ideas turned into alternatives, they were documented, shown to the affected party, and recommendations were collected from all corresponding parties before making the decision. The responsibility of each decision-making level depended on the amount of money a decision contained. If a decision couldn't be made at a low level or an amount of money was exceeded, the decision got escalated to the next hierarchical level. For 
example, the cluster group was limited to decisions of up to US\$ 50,000. Most decisions were made on the captain's level and approximately only $2 \%$ of the decisions were escalated to senior level management. If decisions impacted the design, schedule, cost, or sustainability, they were escalated to level (3). In level (4) the director of design and construction was involved. Issues that were decided at the management committee were things such as the redesign of the interior. Besides the clear structure, a timeframe to make a decision was restricted. For example, the captains level had three days to decide and the senior leadership had one week. The bottom-up approach resulted in people spending less time on ideas that wouldn't be realized, faster and on time decision-making and higher productivity. The design process ended successfully because the decisionmaking process produced US\$ 55M worth of design changes, as additional value.

\section{CASE 3}

The Lower Thames Crossing is a complex infrastructure project located east of London. It will consist of a double bored tunnel with 13.2 miles of connecting roads. The project will create $70 \%$ extra road capacity across the river, connecting Kent with Essex and creating growth in the local area. In 2016 the project was out in consultation and received 47,000 responses. This led to the Preferred Route Announcement in 2017 and currently the project is in preliminary design preparing for the statutory consultation and DCO application. The preliminary design phase will refine the designs from the options phase and thereby several decisions will be made. It is crucial that these decisions take all considerations into account, for example stakeholders that expressed concerns, environmental considerations, traffic flow, safety in operations and so forth. It is also important that the decisions are transparent and documented to be able to understand the current state of design during consultation. Therefore, a design decision process based on principles from CBA was designed to handle decisions in a structured and efficient way. The first step in the process is to agree whether it is a decision that includes several disciplines. Thereafter the decision is scheduled through the LPS to ensure interfaces with other important decisions are considered. Often the decision is split into two workshops: (1) an engineering workshop where disciplines co-design and discuss alternatives that all meet the minimum criteria and (2) a decision workshop where relevant disciplines agree on key factors, criteria and attributes relevant for the decision, and make an assessment ending up in a recommendation for the decision. The recommendation thereafter goes through an agreed approval process with the client. The CBA process has been adapted throughout the project as a way to take cross-disciplinary decisions. The method has shown to be an efficient way to reach consensus on decisions. Furthermore, the structured nature of the assessment leads to value adding ideas and solutions and is now regarded as a value management tool. The team has explained that this method has given confidence that the decisions are of high quality delivered through an efficient process.

\section{CASE 4}

The project is an IT campus that will be located in California. It is a challenging and iconic building consisting of 595,000 sf, and several other amenities for the city, such plazas, recreation areas, and parking spaces. It must comply with stringent city 
requirements. The project decision-making method during design evolved from WRC and not a structured decision-making process to the systematic implementation of CBA and A3s. This happened after an intervention led by the project manager with the support of lean coaches. The structure of the decision-making process after the implementation of lean thinking, was developed through several collaborative decisions meetings. The meetings to discuss decisions were held remotely, due to the nature of the project having several locations of designers (California, New York, and London). The timing of decisions was informed by LPS; decisions were pulled by the design planning process. For each meeting, the team followed a structured conversation process to identify the decision to be made, the factors and criteria for evaluation according to target values for design, possible design alternatives, attributes of the alternatives, and advantages of the alternatives. Cost was treated separately as a constraint, and finally the team agreed on a recommended alternative based on advantages, which were assessed as valuable to the client and community. Value and costs of each alternative were given to the owner for review. Many decisions were made simultaneously. Each collaborative decision meeting lasted for about 2 hours each, and any decision could require multiple meetings. The governance process was initiated by the team identifying decisions to be made from issues discovered in the design process or opportunities for improving the design, according to the plan. Then, the team would recommend a solution with a rationale for it and the owner would make the final decision. The documentation of the decision was based on an $\mathrm{A} 3$ report that contains CBA decision principles. All team members could write parts of the decision in a "virtual" A3 that is publicly shared for project members.

\section{FINDINGS}

In summary, a decision-making process must support an adequate exchange of information and effective coordination. Table 3 provides an overview of the discussed decision-making processes based on the: (1) decision-making method, (2) structure of the decision-making process, (3) governance process, and (4) documentation process.

All four projects used LPS, BIM and the big room concept (case 4 virtually). In case 3 and 4 the decision-making was strongly connected to the LPS, whereas in case 1 and 2 the actions of a decision were connected to the LPS, but not the decision itself. Tracking the tasks throughout the decision-making process through LPS helped the teams to stay focused and make decisions on time, especially if the owner participates in the LPS. For example, decisions are cross disciplinary which means all disciplines need to prepare thoroughly before the decision can be made. The LPS makes it clear what the required timing is and how much time is given to prepare. In case 1 and 4, A3 reports were used to represent the decision in a clear manner. In all cases the governance process was hierarchical, with the final decision made by the owner. However, in comparison to the other cases, case 2 provided a very clear structured decision-making process with hierarchical levels depending on decisions' impact on design, quality, schedule, and cost, and the amount of money the decision required. It was always transparent who was accountable for a decision and who participated in the decision-making. Members of the project team where empowered and had the autonomy to make decisions. Thus, "for one 
of the first times in their career [senior managers] were required to actually make senior management decisions, based on hard data, and that worked" (Interviewee, 11/03/2014).CBA was used as the decision-making method in cases 3 and 4. Team members participating in a CBA workshop in case 3 felt assured that CBA is an efficient group decision-making method. It was beneficial to separate opinions with facts (attributes). The process made it possible for different personality types to contribute, and through evaluations, the participants expressed that they felt heard. Furthermore, ideas for further improvements and value adding opportunities were identified and agreed on in workshops. In case 4 , the design team reported better decisions were made, resulting in an $11 \%$ cost saving for the client, and less confusion and iterations in the design process. Also, decisions were contrasted against the Target Value Delivery (TVD) targets defined by the owner and design team and new alternatives were created to deliver higher value according to these targets and compared against the baseline design.

Table 3: Overview of the findings

\begin{tabular}{|c|c|c|c|c|}
\hline Case & $\begin{array}{l}\text { Decision- } \\
\text { making method }\end{array}$ & $\begin{array}{l}\text { Structure of the decision- } \\
\text { making process }\end{array}$ & $\begin{array}{l}\text { Governance } \\
\text { process }\end{array}$ & $\begin{array}{c}\text { Documentation of the } \\
\text { decision }\end{array}$ \\
\hline $\begin{array}{c}\text { UCSF } \\
\text { Mission Hall }\end{array}$ & $\begin{array}{c}\text { no specific } \\
\text { method, but A3s }\end{array}$ & $\begin{array}{l}\text { Generic process, no } \\
\text { specific structure }\end{array}$ & $\begin{array}{l}\text { Hierarchy approval } \\
\text { process }\end{array}$ & $\begin{array}{l}\text { Partly Documentation via } \\
\text { A3 report }\end{array}$ \\
\hline $\begin{array}{l}\text { UCSF } \\
\text { Medical } \\
\text { Centre }\end{array}$ & $\begin{array}{l}\text { no specific } \\
\text { method }\end{array}$ & $\begin{array}{l}\text { Straight structure with } \\
\text { different levels, clearly } \\
\text { defined responsibilities }\end{array}$ & $\begin{array}{l}\text { Integrated bottom- } \\
\text { up process with } \\
\text { hierarchical levels }\end{array}$ & $\begin{array}{l}\text { Documentation of } \\
\text { alternatives and decision } \\
\text { in a specific template }\end{array}$ \\
\hline $\begin{array}{l}\text { Lower } \\
\text { Thames } \\
\text { Crossing }\end{array}$ & CBA & $\begin{array}{c}\text { Generic process for taking } \\
\text { decisions integrated with } \\
\text { LPS }\end{array}$ & $\begin{array}{l}\text { Hierarchy approval } \\
\text { process }\end{array}$ & $\begin{array}{l}\text { Documentation of } \\
\text { alternatives and } \\
\text { recommendation in a } \\
\text { specific template }\end{array}$ \\
\hline $\begin{array}{l}\text { IT Campus } \\
\text { Project }\end{array}$ & CBA with A3s & $\begin{array}{c}\text { Collaborative process } \\
\text { integrated with LPS and } \\
\text { TVD }\end{array}$ & $\begin{array}{l}\text { Horizontal among } \\
\text { design team, owner } \\
\text { made final decision }\end{array}$ & $\begin{array}{c}\text { Shared A3 reports, } \\
\text { Systematic collaborative } \\
\text { documentation }\end{array}$ \\
\hline
\end{tabular}

\section{DISCUSSION}

A structured group decision-making process enables more people with different opinions to participate in the discussion. In accordance to the characteristics of an effective decision-making process defined in the literature review, the four cases achieved a different degree of intensity regarding positive interdependence, face-to-face promotive interaction, individual accountability, social skills, and group processing (receive feedback, analyze and reflect, improve, celebrate). Besides and although trust was not particularly measured, the authors observed a high level of trust among team members which affected the decision-making process in all four cases and therefore define trust as another factor impacting the decision-making process. Using CBA supports the team to identify must have criteria at the beginning of the decision-making process, which avoids wasting time in alternatives that will be discarded later. It provides transparent documentation which helps to discuss alternatives and create a shared understanding. Moreover, CBA helps to write the rationale of a decision which is important to document it in a proper way for final approving, and bad documentation can lead to mistrust in the 
decision-making process. Expectations to the different disciplines and professions relevant for the decision are clear, and by separating facts provided by subject matter of experts from opinions better quality decisions will be made. The structured process leads to value adding opportunities. For example, advantages from one alternative can be added to another alternative without or with few additional costs. Therefore, the decisionmaking process should be considered as an important part of the value management activities on the project. In addition, it is more important to map the interrelations between decisions than between deliveries, because if the decisions are coordinated, the deliveries (e.g. reports and analysis) will reflect this.

Thus, based on these findings, the authors give the following recommendations for an effective decision-making process: (1) Define a clear structured decision-making and governance process, and define responsibilities for every hierarchical level. (2) Use an integrated bottom-up process for decision approval. (3) Use CBA as a method to choose between alternatives. (4) Connect the timing of the decisions with the LPS. (5) Document and share decisions among the team using a clear defined template such as A3s. (6) Test the value of the alternatives against TVD identified by the project team.

\section{CONCLUSION}

This paper showed and discussed the value of an effective decision-making process and presented recommendations on how a decision-making process should be designed by answering three research questions. The first research question was answered based on literature and findings from the case studies. In summary, value is created when decisions are made within targets and constraints. Collaborative decision-making creates value, because group decisions increase the quality and the acceptance of the decision, interdependence and effects on certain team members are discussed, resulting in an easier implementation process. Thus, it is essential to address the decision-making process and clarify how decision will be made on a project. For effective decision making, (second research question) coordination, a clear structure (e. g. Dean and Sharfman 1996; Johnson and Johnson 2009), and a governance process that fully utilizes the team's resources, using an integrated bottom-up approach, are necessary. Furthermore, a transparent decision-making method such as CBA that supports the involvement and the collaborative discussion about alternatives is required. Linking CBA with LPS and TVD provides effectiveness and reduces waste in the design process.As stated in the discussion section, the decision-making process should be designed to involve different hierarchical levels and to enhance the effectiveness of the team based on the five points listed (third question).

The findings are limited to four cases and the full potential of Lean methods in the decision-making process has not been fully tested in design. A more structured research comparing different project types regarding decision-making in combination with Lean methods such as CBA could give transparency to the benefits and strategies for implementation. 


\section{ACKNOWLEDGEMENT}

The authors want to thank the interviewees, the German Academic Exchange Service (DAAD - Deutscher Akademischer Austausch Dienst), the Institute of Technology and Management in Construction (TMB) at KIT, the Product Production System Laboratory (P2SL) at UC Berkeley and the UCSF Capital Program Department (REPCAPS) for supporting this research. Furthermore, the authors also want to thank the project team at Lower Thames Crossing and IT Campus project as well as LeanProject consulting.

\section{REFERENCES}

Arroyo, P., Tommelein, I. D., and Ballard, G. (2014). Comparing AHP and CBA as decision methods to resolve the choosing problem in detailed design. ASCE J. Constr. Eng. Manage., 141(1), doi: 10.1061/(ASCE)CO.1943-7862.0000915.

Arroyo, P., Fuenzalida, C., Matthew, A.A., Hallowellc, M.R. (2016). "Collaborating in decision making of sustainable building design: An experimental study comparing CBA and WRC methods." Energy and Buildings, 128, 132-142.

Dean, J.W., and Sharfman, M-P. (1996). "Does decision process matter? A study of strategic decision-making effectiveness.” Acad. Manag. J., 39(2), 368-396.

Dickens, L., and Watkins, K., (1999). "Action Research: Rethinking Lewin." Management Learning, 30(2), 127-140.

Ellis, D.G., and Fisher, A.B. (1994). Small group decision making: communication and the group process. McGraw-Hill, 4. ed., New York.

Hirokawa, R.Y., (1990). "The role of communication in group decision-making: A taskcontingency perspective.” Small Group Research, 21, 190-204.

Hirokawa, R.Y., Erbert, L, and Hurst, A. (1996). "Communication and group decision making effectiveness." In: Guzzzo, R.A. [eds.] Improving group decision making in organization: approaches from theory and research. 2nd ed., Academic Pr., NY.

Guzzzo, R.A., (1982). Improving group decision making in organization: approaches from theory and research. Academic Pr., New York.

Johnson, D.W., and Johnson, F.P. (2009). Joining together: Group theory and group skills. 10. ed., Pearson, Upper Saddle River, NJ [u.a.].

Kolb, M., and Boos, M. (2009). "Facilitating Group Decision-Making: Facilitator's subjective theories on group coordination. Forum Qualitative Social Research, 10(1).

Kpamma, Z. E., Adinyira, E., Ayarkwa, J., and Adjei-Kumi, T. (2016). Application of the CBA Decision System to Manage User Preferences in the Design Process. Journal of Professional Issues in Engineering Education and Practice, 142(1).

Mayring, P. (2010). Qualitative Inhaltsanalyse: Grundlagen und Techniken. Vol. 11.Beltz, Weinheim und Base.

Salvatierra-Garrido, J., Pasquire, C., and Miron, L. (2012). "Exploring Value Concept Through the IGLC Community: Nineteen Years of Experience" 20th Conf. of the Int. Group for Lean Construction. San Diego, USA.

Schöttle, A., and Arroyo, P. (2017). Comparison of Weighting-Rating-Calculating, Best Value, and Choosing by Advantages for Bidder Selection. ASCE J. Constr. Eng. Manage., 143(8). https://doi.org/10.1061/(ASCE)CO.1943-7862.0001342. 
Suhr, J. (1999). The choosing by advantages decisionmaking system. Quorum, Westport.

Tzortzopoulos, P., and Formoso, C.T. (1999), "Considerations on Application of Lean Construction Principles to Design Management" 7th Conf. of the Int. Group for Lean Construction. Berkeley, USA.

Van Wee, B., and Priemus, H. (2017). Megaproject decision making and management. In: Flyvbjerg, B. (eds.). The Oxford Handbook of Megaproject Management, Oxford University Press, 118-136.

Yin, R.K. (2014). Case study research Design and Methods.5th ed., Saga, Los Angeles. 